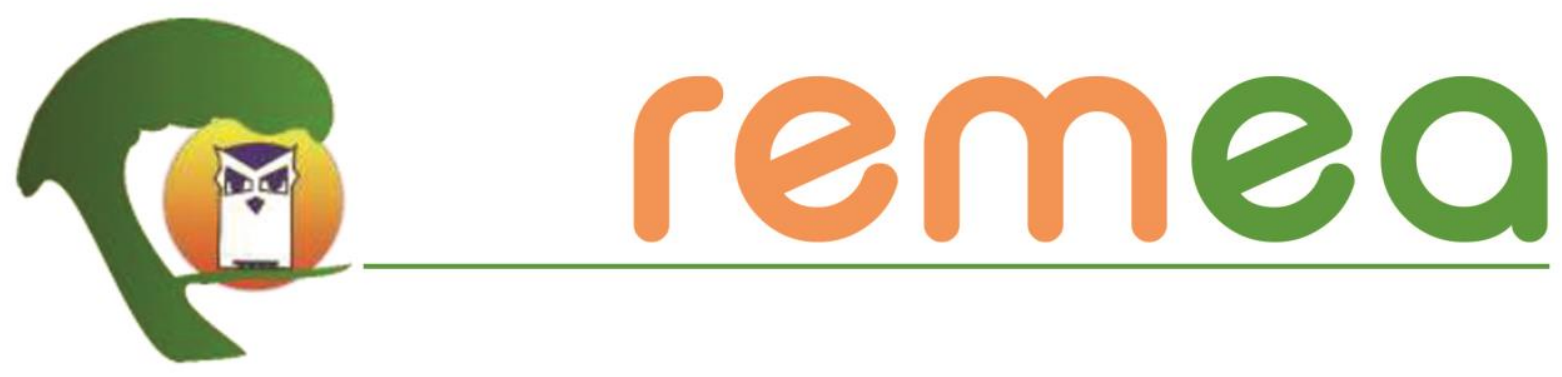

\title{
Educação ambiental nas redes educativas do grupo de pesquisa Territórios de Aprendizagens Autopoiéticas
}

\author{
Soler Gonzalez ${ }^{1}$ \\ Universidade Federal do Espírito Santo \\ ORCID: https://orcid.org/0000-0003-2572-5449 \\ Andreia Teixeira Ramos ${ }^{2}$ \\ Universidade Federal do Espírito Santo \\ ORCID: https://orcid.org/0000-0002-3682-3450
}

Resumo: Este texto aborda as andarilhagens do grupo de pesquisa Territórios de aprendizagens autopoiéticas (CNPq). Assim sendo, apresentaremos as produções acadêmicas e as discussões epistemológicas e metodológicas que surgiram com as pesquisas realizadas com as comunidades tradicionais que vivem em áreas de manguezais; docentes e estudantes da educação básica; docentes e graduandos das licenciaturas e

\footnotetext{
${ }^{1}$ Professor Adjunto do Centro de Educação da Universidade Federal do Espírito Santo. Professor permanente do Programa de Pós-Graduação do Mestrado Profissional em Educação - PPGMPE. Doutor em Educação pelo Programa de Pós-Graduação em Educação da Universidade Federal do Espírito Santo (2010-2013). Líder do Grupo de Pesquisa "Territórios de Aprendizagens autopoiéticas" (CNPq) e do Projeto de ensino, pesquisa e extensão "Narradores da Maré" do Centro de Educação da Universidade Federal do Espírito Santo. Pesquisador do Grupo de pesquisa (CNPq) "Ecologias do Narrar" da Universidade Federal do Rio de Janeiro (UFRJ). E-mail: solergonzalez2011@gmail.com

${ }^{2}$ Professora do curso de Licenciatura Intercultural Indígena (Prolind) da Universidade Federal do Espírito Santo. Mestra em educação pelo Programa de Pós-Graduação em Educação da Universidade Federal do Espírito Santo (2011-2012/CAPES). Doutora em educação pelo Programa de Pós-Graduação em Educação da Universidade de Sorocaba (2015-2018/CAPES). Líder do Grupo de Pesquisa "Territórios de Aprendizagens autopoiéticas" (CNPq) e do Projeto de ensino, pesquisa e extensão "Narradores da Maré" do Centro de Educação da Universidade Federal do Espírito Santo. Pesquisadora do Grupo de pesquisa (CNPq) "Ecologias do Narrar" da Universidade Federal do Rio de Janeiro (UFRJ). Pesquisadora pós-doc do Grupo de Pesquisa (CNPq) "Currículos cotidianos, redes educativas, imagens e sons" do Programa de Pós-Graduação em Educação (Proped) da Faculdade de Educação da Universidade do Estado do Rio de Janeiro. E-mail: andreiatramos.ea@gmail.com
} 
mestrandos do Mestrado Profissional em Educação da Universidade Federal do Espírito Santo. Nosso interesse é expor as contribuições do grupo com a pesquisa narrativa, a pesquisa cartográfica em estudos com os cotidianos e a perspectiva ecologista de educação, entrelaçando a educação das relações étnico-raciais com a educação ambiental, tecidas nos cotidianos escolares e em outras redes educativas.

Palavras-chave: Educação ambiental; estudos com os cotidianos; redes educativas.

\section{La educación ambiental en las redes educativas del grupo de investigación Territorios de Aprendizaje Autopoyéticos}

Resumen: Este texto aborda las andanzas del grupo de investigación Territorios de aprendizajes autopoiéticas (CNPq). Abordaremos las producciones académicas y las discusiones epistemológicas y metodológicas que surgieron con las investigaciones realizadas con las comunidades tradicionales que viven en áreas de manglares, maestros y estudiantes de educación básica, profesores y estudiantes de graduación y estudiantes de la Maestría Profesional en Educación de la Universidad Federal de Espírito Santo. Nuestro interés es exponer las contribuciones del grupo con la investigación narrativa, con la investigación cartográfica, en estudios con los cotidianos y la perspectiva ecologista de educación, entrelazando la educación de las relaciones étnico y raciales con la educación ambiental, tejidas en los cotidianos escolares y en otras redes educativas.

Palabras clave: Educación ambiental; estudios con los cotidianos; redes educativas.

\section{Environmental Education in the educational networks of the Autopoietic Learning Territories research group.}

Abstract: This text addresses the wanderings of the Autopoietic Learning Territories research group (CNPq). We will address the academic productions and the epistemological and methodological discussions that emerged with the research carried out with traditional communities living in areas of mangroves, teachers and students of basic education, teachers and students of graduation and master's degrees in the Professional Masters in Education at the Federal University of Espírito Santo. Our interest is to expose how the group's contributions to narrative research, cartographic research, studies with everyday life and the ecological perspective of education, interweaving the education of ethnic-racial relations with environmental education, woven into everyday school life and in others educational networks.

Keywords: Environmental education; studies with everyday life; educational networks.

\section{Palavras iniciais}

Este texto discorre acerca das andarilhagens do grupo de pesquisa Territórios de aprendizagens autopoiéticas $(\mathrm{CNPq})^{3}$. Para tanto, apresentaremos os processos de

3 Ressaltamos que as atividades acadêmicas do Grupo de Pesquisa "Territórios de aprendizagens autopoiéticas" (CNPq) são articuladas às práticas pedagógicas do Projeto de Extensão "Narradores da Maré", registrado em 2014, na Pró-Reitoria de Extensão (Proex) da Universidade Federal do Espírito Santo, o qual se desmembra também em pesquisas de iniciação científica, ensino, trabalhos de conclusão de curso e 
constituição do grupo e das linhas de pesquisa decorrentes das participações e produções acadêmicas no âmbito local e nacional, assim como as ações de ensino, pesquisa e extensão que estão vinculadas ao grupo. Assim sendo, pensamos andarilhagem a partir do dicionário de Paulo Freire:

\begin{abstract}
Somos humanos porque aprendemos a andar. Somos humanos porque aprendemos a pendular entre um "estar aqui" e um contínuo "partir", "ir para". Entre os que andam, viajam e vagam, há os que se deslocam porque querem (os viajantes, os turistas), os que se deslocam porque creem (os peregrinos, romeiros), os que se deslocam porque precisam (os migrantes da fome, os exilados), e há os que se deslocam porque devem (os "engajados" - para usar uma palavra cara aos dos anos 1960 - os "comprometidos com o outro, com uma causa"). Paulo Freire pertenceu às duas últimas categorias (BRANDÃO, 2010, p. 41).
\end{abstract}

Desse modo, como Paulo Freire, desejamos apresentar nossas andarilhagens expondo as produções acadêmicas e as discussões epistemológicas e metodológicas que surgiram com as pesquisas realizadas com as comunidades tradicionais que vivem em áreas de manguezais, as quais são sujeitos praticantes (CERTEAU, 2008), históricos (FREIRE, 2009), das comunidades pesqueiras tradicionais e grupos sociais: pescadores, desfiadeiras de siris, catadores de caranguejos, paneleiras, congueiras, cantadeiras e organizações não governamentais (ONGs), envolvendo docentes e estudantes da educação básica, docentes e graduandos das licenciaturas do Centro de Educação da Universidade Federal do Espírito Santo (UFES) e mestrandos do Mestrado Profissional em Educação da UFES.

Nosso interesse é expor as contribuições do grupo com os estudos de Humberto Maturana (1999, 2006); com a pesquisa narrativa de Marcos Reigota (2016) e Inês Barbosa de Oliveira (2010); com os estudos com os cotidianos nas redes educativas de Nilda Alves (2010, 2019) e de Carlos Eduardo Ferraço (2003), a partir da educação ambiental e da perspectiva ecologista de educação de Marcos Reigota $(1999,2012)$, entrelaçada à educação das relações étnico-raciais com Nilma Lino Gomes (2011) e bell hooks (2013) e à literatura de Carolina Maria de Jesus (2014) e de Conceição Evaristo (2016a, 2016b, 2017a, 2017b, 2017c, 2017d).

dissertações de mestrado profissional em educação. O nome do Projeto 'Narradores da maré' se inspira no filme de 2003 "Narradores de Javé". Maiores informações estão nas referências no final do texto. 
Para tanto, este artigo busca traçar algumas das andarilhagens e trajetórias epistemológicas e metodológicas do grupo de pesquisa, as quais foram responsáveis por fazer proliferar encontros, desencontros, descobertas e aprendizagens com diferentes perspectivas de educação ambiental. Antes mesmo da formalização do grupo no papel, nas andarilhagens iniciais em 2012, fazíamos o grupo acontecer nos encontros com as exposições, ocupações, livros, discos, eventos, viagens, pessoas, grupos (GUIMARÃES; KRELLING; BARCELOS, 2010; GUIMARÃES et al., 2012) e acontecimentos cotidianos, os quais ainda movimentam nossas ideias e posicionamentos acadêmicos. Passados os primeiros anos, com a possibilidade de um lugar para realizarmos os encontros, intensificamos ainda mais o que fazíamos, contando agora com outras colaboradoras e colaboradores, desejosos em pensar os territórios de aprendizagens que nos constituem como pessoas; cidadãos e cidadãs; professores e professoras; pesquisadores e pesquisadoras da Educação e da Educação Ambiental.

Essas andarilhagens iniciais são inspirações para o fazer pesquisa dos membros do grupo, pois, possibilitam pensar as redes educativas presentes nos diferentes territórios da vida cotidiana, que atravessam também as trajetórias acadêmicas e do fazer pesquisa nos espaçostempos. Como andarilhos, durante nossas passagens pelo mestrado e doutorado em Educação, percorremos diferentes lugares, conhecemos pessoas e pudemos participar das agendas acadêmicas com eventos, artigos, minicursos, oficinas, formações e exposições.

Apresentaremos, neste artigo, um pouco dessas andarilhagens e algumas das trajetórias do Grupo de pesquisa "Territórios de aprendizagens autopoiéticas" com a Educação Ambiental, desde seu estágio embrionário até o presente momento. Atualmente podemos denominar essa atitude andarilha como atitude ecologista, fazendo uma menção ao livro "Ecologistas" do professor Marcos Reigota (1999) e ao livro "Geografia dos afetos: cartas, cartões postais, diário de campo e caderno de uma pesquisadora", da professora Andreia Ramos Teixeira (2021). Essas obras nos fazem pensar a potência dos acontecimentos em nossa vida cotidiana no fazer pesquisa, pensando, também, com inspirações na pedagogia freireana (FREIRE, 2011a, 2011b, 2014a, 2014b, 2015a, 2015b; FREIRE; GUIMARÃES, 2011a, 2011b, 2011c), a educação e a educação ambiental como 
prática da liberdade. Além disso, abordaremos, no decorrer do texto, as trajetórias e os territórios de aprendizagens autopoiéticos que habitamos e que nos atravessam (GONZALEZ; RAMOS, 2011, 2013a, 2013b, 2015a, 2015b, 2016, 2019a; RAMOS; TRISTÃO, 2014; GONZALEZ; TRISTÃO, 2014; RAMOS, 2020).

\section{Caminhos investigativos}

Nas primeiras peregrinações acadêmicas, principalmente pelos desvios e desencontros, encontramos os estudos do biólogo chileno Humberto Maturana e de seu discípulo Francisco Varela. Lamentamos o fato de não termos conhecido Humberto Maturana ${ }^{4}$ pessoalmente nem ao Instituto Matríztico no Chile. Com os estudos de Maturana e Varela, trouxemos para o debate do campo da Educação Ambiental (e da Educação) nosso posicionamento para pensarmos a Educação ambiental numa perspectiva autopoiética na formação de educadores/as (RAMOS; GONZALEZ, 2012), artigo publicado na Revista PróDiscente do Programa de Pós-Graduação em Educação da UFES.

Esse posicionamento adveio com "a possibilidade de pensarmos a Educação Ambiental numa perspectiva autopoiética em redes de conversações cotidianas nas escolas e na formação de professores/as" (RAMOS; GONZALEZ, 2012, p. 52). Aproveitamos para ressaltar que Humberto Maturana, desenvolveu as primeiras pesquisas junto com Francisco Varela, na década de 1970, aproximando Biologia e Epistemologia e reforçando a inseparabilidade entre viver e conhecer, assim suas concepções como as noções de Biologia do Amor e Biologia do Conhecer, com suas reformulações teóricas, questionam a ciência moderna.

Esse primeiro estudo realizado suscitou provocações, inquietações e o desejo de andarilhar por encontros e eventos acadêmicos, buscando outras leituras, entrevistas e vídeos do autor e de pesquisas que abordassem as ideias de Maturana e suas contribuições para os estudos da cognição e da educação. Em 2012, fomos a São Paulo, precisamente a Campinas, na Unicamp, apresentar o trabalho Educação Ambiental e formação de professores numa perspectiva autopoiética (GONZALEZ; RAMOS; RANGEL, 2012a) no

\footnotetext{
${ }^{4}$ No dia 6 de maio de 2021, Humberto Maturana faleceu aos 92 anos em Santiago no Chile.
} 
Encontro Nacional de Didática e Práticas de Ensino (ENDIPE). Na ocasião, conhecemos um pouco o campus universitário e a cidade. Como em todos os eventos, marcamos no caderno de programação o que não poderíamos perder. Foi o caso de um painel temático que contava com a participação do professor Leandro Belinaso Guimarães. Ao final do painel, na saída do prédio, apresentamo-nos, conversamos e ali criamos uma amizade.

Meses depois, ainda em 2012, andarilhamos até Natal no Rio Grande do Norte para apresentarmos o trabalho Educação ambiental numa perspectiva autopoiéticas e as redes de conversações na formação de educadores/as (GONZALEZ; RAMOS; RANGEL, 2012b) na Associação Nacional de Pós-Graduação e Pesquisa em Educação (Anped). À medida que os trabalhos andarilhavam pelos territórios acadêmicos, de pesquisa, ensino e formação, questões e contribuições foram incorporadas, de modo que, a partir dos diálogos com as ideias de Maturana, aproximávamo-nos do potencial das conversas nos cotidianos escolares. Assim, as perspectivas de educação ambiental (e de educação) que o grupo de pesquisa trazia para a conversa, eram no sentido de reconhecer e considerar as redes cotidianas como espaços de convivência, por meio dos quais a aprendizagem acontece de modo permanente. Com essas andarilhagens embrionárias, de um grupo de pesquisa, encontramos questões provocativas, a partir dos nossos estudos, que nos motivaram como pesquisador e pesquisadora no campo da Educação e da Educação Ambiental.

Pousamos na cidade do Rio de Janeiro, que tem sido palco de várias relações solidárias e de cooperação, desde quando fazíamos pós-graduação, e palco também de andarilhagens que ajudaram a alicerçar as bases éticas, políticas e epistemológicas do grupo de pesquisa. Os primeiros passos por lá foram em 2012 nas atividades da Rio + 20 na Cúpula do Povos, e em 2013, no VII Seminário Internacional - As Redes Educativas e as Tecnologias: transformações e subversões na atualidade, com o trabalho Humberto Maturana e seus atravessamentos com a educação ambiental e formação de professores/as (GONZALEZ; RAMOS, 2013a).

A discussão que nos movia e que nos inquietava era a de se pensar na possibilidade de uma sociedade sustentável imersa em uma sociedade de controle, individualista, e na cultura da competição que atravessam nossas relações sociais e os cotidianos escolares, 
pois, de acordo com o pensamento de Maturana, nós nos constituímos historicamente e biologicamente como humanos na cooperação, sendo a competição uma invenção cultural humana, portanto, não biológica.

Nós temos a biologia do compartilhar, e isso se nota na vida cotidiana [...] O compartilhar é em nós um elemento que pertence à nossa biologia, não pertence à cultura. Pelo contrário, vivemos atualmente uma cultura que nega o compartilhar, porque estamos supostamente mergulhados na maravilha da competição (MATURANA, 2006, p. 93).

Nesses fluxos com a nossa condição biológica do compartilhar, dessa Biologia do Amor que nos é ontológica, trouxemos à tona a noção de conhecimento como sendo o que emerge nas conversações, no conviver com o outro, entendendo a conversa e o conversar "como um domínio operacional biológico dos seres humanos constituindo cotidianamente redes de conversações na linguagem" (GONZALEZ; RAMOS, 2013a, p. 9).

Assim, outras questões surgiram tanto a partir das nossas andarilhagens, encontros, desencontros, descobertas e conversas, nas apresentações dos trabalhos, quanto, e principalmente, das andarilhagens suburbanas, nas boemias, sem perder o faro das exposições e eventos culturais pelas cidades e territórios de aprendizagens vividos com a tessitura das geografias dos afetos.

\footnotetext{
Assim, podemos pensar a Educação Ambiental e formação de educadores/as também como redes de conversações? Como nós educadores/as e educandos vivemos e produzimos nossas redes de conversações cotidianas? Como exercitamos nossas relações de aceitação e respeito por si e pelos outros nas tensões e conflitos cotidianos? (GONZALEZ; RAMOS, 2013a, p. 9).
}

Essas reflexões também foram apresentadas no Grupo de Trabalho 22 de Educação Ambiental da ANPEd de 2013 que ocorreu na Universidade Federal de Goiás, com a apresentação das comunicações orais intituladas Educação ambiental entre práticas culturais cotidianas dos mascarados do congo (RAMOS, 2013a) e Educação ambiental autopoiética entre manguezais, redes cotidianas escolares e práticas pesqueiras (GONZALEZ, 2013a), ambas derivadas de pesquisas em educação (PPGE/UFES); a primeira uma dissertação de mestrado (RAMOS, 2013b) e a segunda uma tese de doutorado (GONZALEZ, 2013b). As abordagens dos trabalhos trouxeram interlocuções da educação ambiental com 
as práticas culturais cotidianas, pensando-as enquanto práticas de resistência que produzem modos de vida ancestrais.

A aposta com a Educação Ambiental autopoiética está nas relações de aceitação do outro como legítimo outro na convivência, nas conversas, no fazer com, uma VIDA de menos competição e mais colaboração, culturas de solidariedade e respeito às formas de vida. (RAMOS, 2013a, p. 13).

Nesse cenário, em 2014, continuamos tecendo nossas redes com o artigo Educação Ambiental autopoiética em redes de conversações na vida cotidiana (GONZALEZ; RAMOS, 2014), publicado na Textura - Revista de Educação e Letra da ULBRA -, no dossiê $A$ potência Ambiental da Educação. Nesse contexto, a partir de 2015, tivemos aproximações com outros modos de pensar a educação ambiental por meio do encontro com as pesquisas de Rodrigo Barchi (2009, 2016a, 2016b).

\section{Resultados e discussão dos dados}

Em 2016, o grupo de pesquisa Territórios de aprendizagens autopoiéticas atraiu graduandos interessados em realizar pesquisas em Educação Ambiental, por meio de subprojetos de iniciação científica vinculados ao projeto de pesquisa "Narradores da maré: geografias dos manguezais da Baía de Vitória e a formação de educadores/as". Nesta época, o grupo concentrava suas produções na linha de pesquisa "Educação ambiental e ensino de Geografia", posteriormente, decorrente das andarilhagens teóricas do grupo, registramos outra linha de pesquisa: "Educação Ambiental e Educação das relações étnico-raciais". A seguir, optamos por abordar os subprojetos de iniciação científica ${ }^{5}$ que foram realizados, ressaltando que, além desses subprojetos, tivemos também os trabalhos de conclusão de curso da graduação em Pedagogia e em Geografia-Licenciatura e as ações do Projeto de Extensão Narradores da maré, que juntos contribuíram para ampliar as ações de ensino, pesquisa e extensão do grupo de pesquisa e do projeto Narradores da Maré.

O primeiro subprojeto, intitulado Narradores da Maré: estudo e produção de mapas digitais com os saberes socioambientais e geográficos de comunidades tradicionais dos

\footnotetext{
${ }^{5}$ Para conhecer mais detalhes, consulte o blog, o Facebook e o Instagram do Projeto de ensino, pesquisa e extensão "Narradores da Maré", cujas referências constam no final do texto.
} 
catadores de caranguejos e das paneleiras do Bairro Goiabeiras Velha (GONZALEZ; SILVA, 2016), objetivou mapear saberes geográficos e socioambientais das práticas culturais de catadores de caranguejos e das Paneleiras do bairro Goiabeiras Velha, articulando o ensino de Geografia, cartografia escolar e Educação Ambiental. Para a elaboração deste mapeamento, utilizamos o aplicativo para celulares e smartphones GPS Essenciats ${ }^{6}$, de modo que, para conhecê-lo melhor, realizamos uma oficina com turmas das séries finais do ensino fundamental, na qual os grupos de estudantes puderam criar seus mapas digitais, incluindo informações como trajeto percorrido, pontos de parada para registro de fotos e/ou podcasts do local escolhido, legendas e título do mapa.

Após as experiências com as oficinas, que suscitaram problematizações quanto ao uso dos artefatos tecnoculturais (SOARES; SANTOS, 2012), que são também criadores de currículos nos cotidianos escolares, entramos em contato com o galpão das Paneleiras de Goiabeiras ${ }^{7}$ para conversarmos sobre suas relações ancestrais, culturais e ecológicas com os manguezais. Com a intenção de "narrar a vida e literaturizar a ciência" (ALVES, 2010), apresentamos os dados produzidos no campo da pesquisa com os sujeitos praticantes por meio de cenas cotidianas, que indicam traços de uma cartografia da panela de barro, com suas territorialidades, temporalidades, conflitos e saberes socioambientais e geográficos.

No ano seguinte, orientamos dois subprojetos. O primeiro, intitulado Perspectivas ecologistas nas narrativas contadas pelas paneleiras de Goiabeiras e suas contribuições com a formação de educadores/as (GONZALEZ; LEITE, 2017), consistia em registrar e problematizar os saberes geográficos, históricos, culturais e socioambientais, nas histórias de vida das Paneleiras do bairro de Goiabeiras Velha, que são também sujeitos da história. As bases teórico-metodológicas desse subprojeto se aproximam das pesquisas com o cotidiano (ALVES, 2010), assumindo a atitude metodológica de pesquisador conversador no cotidiano e com inspirações nas narrativas ficcionais (REIGOTA, 1999).

O outro subprojeto, intitulado Narradores da maré: perpetuação dos saberes populares tradicionais dos catadores de caranguejo e das Paneleiras do bairro Goiabeiras

\footnotetext{
${ }^{6}$ Para maiores informações, ver página virtual 'gpsessentials' nas referências finais do texto.

${ }^{7}$ Para obter mais informações, consultar página virtual do Instituto do Patrimônio Histórico e Artístico Nacional (Brasil), Ofício das Paneleiras de Goiabeiras. Disponível nas referências finais do texto.
} 
Velha através de vídeo documentário experimental (GONZALEZ; NOGUEIRA, 2017), objetivou registrar e problematizar os saberes geográficos, históricos, culturais e ambientais presentes nas narrativas e histórias de vida dos catadores de caranguejo. As bases teóricometodológicas são semelhantes ao subprojeto anterior e o resultado consistiu na elaboração e edição de um vídeo documentário experimental com a participação de um antigo catador de caranguejo do bairro.

No ano de 2018, abordamos a seguinte temática na iniciação científica: Educação ambiental, meio ambiente, representações sociais, narrativas e práticas pedagógicas nos cotidianos escolares (GONZALEZ; LEITE, 2018). As ações aconteceram com um grupo de professores/as da rede pública de ensino de escolas da Região Metropolitana da Grande Vitória/ES, situadas próximas ou em áreas de proteção ambiental. O objetivo central da pesquisa consistia em investigar e problematizar as representações sociais que circulam e que são produzidas por professores e professoras, tanto em suas práticas pedagógicas docentes como em suas vidas cotidianas, levando em consideração não só as representações sociais de "meio ambiente" e "educação ambiental" como também os principais "problemas socioambientais" da Grande Vitória.

$\mathrm{Na}$ produção de dados, utilizamos narrativas, conversas, entrevistas conversadas e gravadas sobre a poluição dos manguezais, rios e mares; as enchentes; o consumismo desenfreado; o desmatamento da Mata Atlântica; a intensa urbanização; a queima da turfa no município de Serra/ES; a tragédia-crime da Samarco em Mariana e o "pó preto" das atividades siderúrgicas locais, tendo como base ética, política e pedagógica as dimensões freireanas, da dialogicidade e do inacabamento dos sujeitos nos processos educativos e nas pesquisas em Educação Ambiental.

Em 2020, em pleno contexto da pandemia do novo Coronavírus, realizamos o subprojeto Momentos e acontecimentos da história ambiental e das tragédias ecológicas na Bacia do Rio Doce, narrados por meio de fotografias, notícias e vídeos (GONZALEZ; SILVA, 2020). O objetivo consistiu em problematizar as contribuições políticas, pedagógicas, históricas e ecológicas, por meio de fotografias e reportagens de jornais de circulação local, que registram impactos e tragédias-crimes ecológicas relacionados com a atividade 
mineradora na bacia do rio Doce, indicando registros de uma história ambiental. Para tanto, a metodologia envolveu aproximações com as fotografias e reportagens de jornais que assumem aqui a função de imagensnarrativas sobre os registros de acontecimentos históricos ocorridos na bacia do Rio Doce. Nessa pesquisa, reunimos, organizamos e analisamos reportagens de jornais de circulação estadual do período de 1980 até a tragédiacrime em Mariana em 2017.

As questões que nos moveram nesse subprojeto foram: de que forma os documentos, arquivos históricos e os meios de comunicação contribuem para conhecermos os momentos e acontecimentos da história ambiental e dos crimes ecológicos decorrentes das atividades mineradoras na bacia hidrográfica do rio Doce? Como as imagens, documentos, reportagens e vídeos narram essa história ambiental? O que os/as moradores/as ribeirinhos, indígenas, quilombolas, pescadores e agricultores têm a dizer sobre a tragédia-crime da Samarco em 2015, causada pelo rompimento da barragem de Bento Rodrigues, na cidade de Mariana? Como esses acontecimentos não são narrados e divulgados pelas reportagens de jornais? Que políticas de narratividades (GONZALEZ, 2013b) são praticadas pelos discursos midiáticos e de que modo essas narratividades permeiam os contextos educativos e formativos?

A apresentação dos resultados se deu em forma de narrativas ficcionais (REIGOTA, 1999), abordando os acontecimentos da história ambiental nas décadas de 80-90 e dos anos 2000 até 2017. Após a análise de mais de 150 notícias e reportagens de jornais locais, os dados encontrados com a pesquisa documental indicam que, mesmo com toda a sua beleza e relevância história, ecológica; mesmo sendo uma região reconhecidamente singular por reunir povos indígenas, ribeirinhos e quilombolas; mesmo com tudo isso, a bacia do rio Doce agoniza há décadas e conclama pela proteção e recuperação do Watú, nome pelo qual o rio é conhecido pelo povo Krenak. O Povo de Watú considera o rio um parente ancestral com grande significância para a cultura e o modo de vida Krenak.

Realizamos ainda em 2020, outro subprojeto, com o intuito de trazer esse triste e trágico crime ecológico, intitulado Vozes sufocadas: histórias e narrativas de pescadores, quilombolas e indígenas afetados pelo desastre ecológico de Mariana e a pandemia da 
Covid-19 na Bacia do Rio Doce (GONZALEZ; SILVA, 2021). . O objetivo consistiu em problematizar as contribuições políticas, pedagógicas, históricas, culturais e ecológicas das narrativas de pescadores, quilombolas e indígenas, registradas em vídeos postados na internet após a tragédia-crime ocasionada pelo rompimento da barragem da mineradora Samarco em Mariana no ano de 2015 e durante o período de pandemia do novo Coronavírus.

Esses relatórios de iniciação científica compuseram 04 capítulos do livro Abordagens territoriais e práticas pedagógicas em territórios pesqueiros (GONZALEZ; RAMOS, 2018) e foram também inspirações para os projetos de pesquisa dos mestrandos e mestrandas do Mestrado Profissional em Educação, que abordaremos a seguir.

A dissertação de Roberto Márcio da Silveira (2019), intitulada Geografia das cores: práticas pedagógicas libertárias e ecologistas em educação nos cotidianos escolares, e o produto educacional (Re)inventando geografias e ecologias com a própria história Cadernocatálogo educativo (SILVEIRA; GONZALEZ, 2019), com narrativas, imagens, fotografias e práticas pedagógicas realizadas nas oficinas "Geografia das cores" e "Sucata que gera vida", apresentaram os espaços dialógicos tecidos nos cotidianos escolares e criaram outras ecologias solidárias.

A seguir apresentaremos três pesquisas de mestrado em educação que foram expostas no Grupo de Trabalho 22 de educação ambiental da Anped Sudeste de 2020 (SANTOS; GONZALEZ, 2020; FARIA; GONZALEZ, 2020; RIBEIRO, 2020). A primeira é a dissertação de Edilene Machado dos Santos (2020), intitulada Cartografias e narrativas das educações ambientais e ecologias insubmissas nos cotidianos das mulheres na bacia do rio Formate, Viana (ES), que objetivou problematizar e cartografar práticas pedagógicas de educação ambiental, realizadas por comunidades e movimentos sociais vianenses, com destaque para as relações comunitárias, afetivas, ecológicas, políticas e pedagógicas em defesa da preservação do rio Formate, dialogando com as noções de bio:grafias (REIGOTA; PRADO, 2008) e de escrevivência (EVARISTO, 2016a) de um grupo de mulheres de

\footnotetext{
${ }^{8}$ O relatório final deste subprojeto ainda será divulgado nos Anais da Jornada de Iniciação Científica, mas o resultado pode ser consultado no blog Narradores da Maré.
} 
movimentos sociais do município de Viana, recorrendo também às contribuições do pensamento freireano como aposta teórica e metodológica e às autoras e escritoras feministas negras como Sueli Carneiro (2019); bell hooks (2013); Conceição Evaristo (2016a); Carolina Maria de Jesus (2014) e Andreia Teixeira Ramos (2018). O produto educacional consiste em um fascículo abordando o encontro-formação com as mulheres participantes dos movimentos sociais vianenses.

Do rio Formate fomos à Reserva de Desenvolvimento Sustentável dos manguezais de Cariacica, com a segunda pesquisa, a dissertação de Fledson Silva Faria (2021), intitulada Educações ambientais políticas com os usos de drones e artefatos tecnoculturais na Reserva de Desenvolvimento Sustentável dos manguezais de Cariacica e nos cotidianos escolares. O trabalho possibilitou a ressignificação dos usos desses artefatos em práticas de educação ambiental nos cotidianos escolares, com a produção de vídeos e imagensnarrativas, com foco na preservação dos manguezais e no engajamento das comunidades locais que vivem às margens da reserva, contribuindo também com o diálogo de saberes com as associações de pescadores e marisqueiros, de moradores, com os projetos sociais locais e com a política municipal de Educação Ambiental.

O produto educacional consiste em um vídeo educativo e formativo intitulado Um olharpassarinho sobre a comunidade, os manguezais e suas ecologias ${ }^{9}$, que apresenta a comunidade de Flexal a partir dos olhares e narrativas dos moradores e pescadores, os quais narram processo de ocupação, lutas e (re)existências locais, abordando também as Unidades de Conservação de Cariacica, com ênfase nos manguezais, no morar e no pescar, permeados por imagens, vídeos e narrativas de aulas de campo e de outras práticas pedagógicas realizadas no manguezal e no bairro. A pesquisa aposta no potencial pedagógico e formativo dos artefatos tecnoculturais e das imagensnarrativas nos cotidianos escolares, em prol de uma educação ambiental política que potencialize a participação da comunidade nas discussões das problemáticas locais.

A terceira pesquisa é a dissertação de Marcia Cristina Mazocco Ribeiro (2021), intitulada Entre fios, nós e educações ambientais: narrativas ecologistas de mulheres de

\footnotetext{
${ }^{9} \mathrm{O}$ endereço do vídeo está disponível nas referências finais do artigo.
} 
Cariacica, que apresenta uma relevante contribuição para a política municipal de Educação Ambiental do município de Cariacica, no sentido de reunir educadoras ambientais, incluindo a autora, que participaram e estão engajadas nos processos de implementação da política municipal, as quais, num movimento freireano de dialogar e aprender com a própria história, narram os contextos e os processos de elaboração da lei municipal de Educação Ambiental.

A pesquisa reúne as narrativas ecologistas das mulheres e educadoras ambientais de Cariacica e as escrevivências de um grupo de mulheres que vivem em diferentes territórios do município, próximos a áreas de preservação ambiental. As narrativas ecologistas das educadoras ambientais, as escrevivências das moradoras que vivem em diferentes regiões ecológicas do município e o processo da pesquisa compõem o produto educacional, organizado em cartões postais e em episódios de Podcats ${ }^{10}$ no canal Narradores da maré, disponível nas plataformas de áudio, trazendo à tona as narrativas dos sujeitos da história e as educações ambientais que nos constituem.

Com a pandemia do novo Coronavírus e a instalação do ensino remoto, pesquisamos possibilidades com os usos dos artefatos tecnoculturais que criam currículos e que, no caso do momento pandêmico, criaram alternativas metodológicas que permitiram a continuidade das pesquisas de mestrado e de iniciação científica e das ações de extensão vinculadas ao grupo de pesquisa. As alternativas encontradas durante a pandemia do Coronavírus, para dar continuidade às ações de ensino, pesquisa e extensão vinculadas ao grupo de pesquisa, foram: a realização do I Ciclo de debates Ecologias Insubmissas, realizado em agosto de 2020, e o 'cineconversas', realizado de março a junho de 2021.

As lives Ecologias Insubmissas aconteceram uma vez por semana, com o propósito de celebrar os 60 anos da publicação de Quarto de Despejo: diário de uma favelada, de Carolina Maria de Jesus (2014), escritora mineira que foi moradora da favela do Canindé, em São Paulo, lugar onde escreveu esse livro. Para integrar e enriquecer o diálogo, foram suscitadas

\footnotetext{
${ }^{10}$ Podcast "é um programa de rádio que pode ser ouvido pela internet a qualquer hora, por meio do celular ou do computador. Com temas e duração variados, o ouvinte pode acessar conteúdos em áudio para se informar, para estudar ou para passar o tempo" de acordo com BRASIL DE FATO MG publicado em 2021. Para escutar o Podcast do Projeto Narradores da Maré consultar o Spotify que está referenciado no final do texto.
} 
inspirações do pensamento do líder indígena Ailton Krenak (2019), no sentido de tentarmos adiar o fim do mundo, e a literatura da escritora mineira Conceição Evaristo. As temáticas das lives foram: Panela de Barro, Congo e amor com os cotidianos escolares (RAMOS, 2018); Aprendendo a andar com a perna de pau do Nico Preto (MAULIN, 2013) e com as narrativas de professores (BARONI, 2016); Quarto de despejo e racismo ambiental (JESUS, 2020) e pandemia e resistências e...; e Encontro com mulheres do rio Formate e do Patrimônio Cultural de Araçatiba, Viana-ES.

Outra alternativa que articulou as ações de ensino, pesquisa e extensão do grupo de pesquisa foi criar episódios de Podcasts do projeto de extensão Narradores da Maré, com o objetivo de mantermos e ampliarmos, mesmo em tempo de pandemia e de ensino remoto, nossas redes educativas, divulgando para a sociedade em geral as ações de extensão, articuladas com os subprojetos de Iniciação Científica e as pesquisa dos/as mestrandos/as do PPGMPE. Os episódios trazem temáticas do grupo de pesquisa e do projeto de extensão relacionados à educação ambiental, à formação de educadores/as, ao ensino de Geografia, história ambiental, problemáticas ecológicas e à educação para as relações étnico-raciais.

As 'cineconversas' foram outro movimento do grupo de pesquisa nesse momento de ensino remoto e distanciamento social. A 'cineconversa' contou com 4 encontros virtuais, em forma de rodas de conversa a partir de obras cinematográficas. Com as 'cineconversas', os participantes foram convidados a produzirem um vídeo de até 1 minuto e a confeccionarem cartões postais virtuais, com a produção de imagens e micronarrativas para os postais. Os curtas-metragens exibidos foram: Mulheres de Barro (2014), com a participação da diretora Edileuza Penha de Souza; Cores e Botas (2010); Kbela (2015); e o curta-metragem capixaba Guri (2019), com a participação do diretor Adriano Monteiro.

\section{Considerações finais}

Desde 2014, o grupo de pesquisa nos mobiliza a pensar os territórios, as culturas e as condições de vida das comunidades e grupos oprimidos e excluídos (GONZALEZ; RAMOS, 2019b; RAMOS; GONZALEZ, 2020). Como dizia Paulo Freire "como um ser inconcluso, consciente de sua inconclusão" (FREIRE, 2014a, p. 101), que afirmamos, junto com 
estudantes, professores/as da Educação Básica, mestrandos/as e orientandos de iniciação científica e de trabalhos de conclusão de curso, nosso comprometimento político, ético e pedagógico, por uma "educação como prática de liberdade" (FREIRE, 2015a), anticolonial e antirracista (HOOKS, 2013), amparados pelas Leis $10.639 / 2003$ e $11.645 / 2008$, as quais estabelecem inclusão no currículo oficial da rede de ensino a obrigatoriedade do ensino do tema da "História e cultura afro brasileira e indígena".

Com as andarilhagens do grupo de pesquisa, aprendemos outras maneiras de caminhar com diferentes educações ambientais, redes educativas e de afetos, encharcadas por outras ecologias, resistências, temporalidades e territorialidades, com potencial descolonizador, a partir de diálogos amorosos, visto que "ninguém educa ninguém, ninguém educa a si mesmo: [seres humanos] se educam em comunhão, mediatizados pelo mundo" (FREIRE, 2014a, p. 96).

São essas andarilhagens que compartilhamos aqui que nos colocaram diante de outros movimentos de aprender e ensinar, proporcionando bons encontros e processos de aprendizagens coletivos e solidários, junto com estudantes, professores e professoras, e comunidades com suas mais diversas expressões culturais e ecológicas. Em 2020 e 2021, o grupo de pesquisa apostou em criar alternativas com os usos de diferentes artefatos tecnoculturais, articulando as ações de ensino, pesquisa e extensão, mesmo que de modo remoto, o que possibilitou a ampliação de nossas redes educativas, bem como a produção de dados das pesquisas do grupo.

\section{Referências}

ALVES, Nilda. Sobre as razões das pesquisas nos/dos/com os cotidianos. In: GARCIA, Leite Regina (org.). Diálogos cotidianos. Petrópolis, RJ: DP et Alii e Faperj, 2010. p. 67-82.

ALVES, Nilda. Sobre as redes educativas que formamos e que nos formam. In: ALVES, Nilda. Práticas pedagógicas em imagens e narrativas: memórias de processos didáticos e curriculares para pensar as escolas hoje. São Paulo: Cortez, 2019. 300 p.

BARCHI, Rodrigo. Uma educação ambiental libertária. Revista eletrônica Mestrado em Educação Ambiental, Revista do PPGEA/Furg-RS, v. 22, jan./jul. 2009. 
BARCHI, Rodrigo. Educação ambiental e (eco)governamentalidade. Ciência \& Educação, Bauru, v. 22, n. 3, p. 635-650, 2016 a.

BARCHI, Rodrigo. Poder e resistência nos diálogos das ecologias licantrópicas, infernais e ruidosas com as educações menores e inversas (e vice-versa). 2016. $321 \mathrm{f}$. Tese (Doutorado em Educação) - Faculdade de Educação, Universidade Estadual de Campinas, Campinas, São Paulo, 2016b.

BARONI, Patrícia Raquel. Sustentabilidades praticadaspensadas: lampejos de pirilampos das escolas de dificílimo acesso de Duque de Caxias/RJ. 2016. 237 f. Tese (Doutorado em Educação) - Universidade Federal do Espírito Santo, Centro de Educação.

BRANDÃO, Carlos Rodrigues. Verbete "Andarilhagem". In: STRECK, Danilo; REDIN, Euclides; ZITKOSKI, Jaime José (org.). Dicionário Paulo Freire. 2. ed., rev. amp. 1. reimp. - Belo Horizonte: Autêntica Editora, 2010.

BRASIL. Lei 10.639, de 09 de janeiro de 2003. Altera a Lei no 9.394 [...] para incluir no currículo oficial da Rede de Ensino a obrigatoriedade da temática "História e Cultura AfroBrasileira" [...]. Brasília, DF: Presidência da República [2003]. Disponível em: http://www.planalto.gov.br/ccivil_03/leis/2003/l10.639.htm. Acesso em: 19 jul. 2021.

BRASIL. Lei 11.645, de 10 de março de 2008. Altera a Lei $n^{\circ} 9.394$ [...] para incluir no currículo oficial da rede de ensino a obrigatoriedade da temática "História e Cultura AfroBrasileira e Indígena". Brasília, DF: Presidência da República [2008]. Disponível em: http://www.planalto.gov.br/ccivil_03/ato2007-2010/2008/lei/l11645.htm. Acesso em: 19 jul. 2021.

COSTA, Larissa. O que é um podcast? Para que serve? Conheça algumas sugestões de programas. BRASIL DE FATO MG, Belo Horizonte, 10 fev. 2021. Disponível em: https://www.brasildefatomg.com.br/2021/02/10/o-que-e-um-podcast-para-que-serveconheca-algumas-sugestoes-de-programas. Acesso em: 06 ago. 2021.

CORES e Botas. Direção: Juliana Vicente. Produção Executiva: Nalu Béco. Roteiro: Juliana Vicente. [S. I.]: Preta Porte, 2010. 1 vídeo (15 min 55 s). Disponível em: https://www.youtube.com/watch?v=LI8EYEygU0o. Acesso em: 12 ago. 2021.

CERTEAU, Michel de. A invenção do cotidiano - artes de fazer. Petrópolis: Vozes, 2008. EVARISTO, Conceição. Insubmissas lágrimas de mulheres. Rio de Janeiro: Malê, 2016a. EVARISTO, Conceição. Olhos d'água. Rio de Janeiro: Pallas, 2016b.

EVARISTO, Conceição. Becos da Memória. Rio de Janeiro: Pallas, 2017a. 
EVARISTO, Conceição. Histórias de leves enganos e parecenças. Rio de Janeiro: Pallas, 2017b.

EVARISTO, Conceição. Poemas da recordação e outros movimentos. Rio de Janeiro: Pallas, 2017c.

EVARISTO, Conceição. Ponciá Vicêncio. Rio de Janeiro: Pallas, 2017d.

FARIA, Fledson Silva; GONZALEZ, Soler. Educação Ambiental com os usos de drones e artefatos tecnoculturais nos manguezais e cotidianos escolares. In: REUNIÃO DA ASSOCIAÇÃO NACIONAL DE PÓS-GRADUAÇÃO E PESQUISA EM EDUCAÇÃO- SUDESTE, 14., 2020, Rio de Janeiro. Anais [...]. Rio de Janeiro: Programas de Pós-Graduação PropED, PPGedu e PPGECC, 2020.

FARIAS, Fledson Silva. Educações ambientais políticas com os usos de drones e artefatos tecnoculturais na reserva de desenvolvimento sustentável dos manguezais de Cariacica e nos cotidianos escolares. Dissertação (Mestrado Profissional em Educação) - Universidade Federal do Espírito Santo, Vitória, 2021, 205 p.

FERRAÇO, Carlos Eduardo. Eu, caçador de mim. In: GARCIA, Regina Leite (org.). Método: pesquisa com o cotidiano. Rio de Janeiro: DP\&A, 2003. p. 157-175.

FREIRE, Paulo. Pedagogia da autonomia: saberes necessários à prática educativa. São Paulo: Paz e Terra, 2009.

FREIRE, Paulo. A importância do ato de ler: em três artigos que se completam. 51. ed. São Paulo: Cortez, 2011a.

FREIRE, Paulo. Cartas à Guiné-Bissau: registros de uma experiência em processo. 5. ed. São Paulo: Cortez, 2011b.

FREIRE, Paulo. Pedagogia do Oprimido. 58. ed. São Paulo: Paz e Terra, 2014a.

FREIRE, Paulo. Pedagogia da indignação: cartas pedagógicas e outros escritos: São Paulo: Paz e Terra, 2014b.

FREIRE, Paulo. Ação cultural para a liberdade e outros escritos. 15. ed. Rio de Janeiro: Paz e Terra, 2015a.

FREIRE, Paulo. Cartas a Cristina: Reflexões sobre minha vida e minha práxis. São Paulo: Paz e Terra, 2015b. 
FREIRE, Paulo; GUIMARÃES, Sérgio. A África ensinando a gente: Angola, Guiné-Bissau, São Tomé e Príncipe. 2. ed. São Paulo: Paz e Terra, 2011a.

FREIRE, Paulo; GUIMARÃES, Sérgio. Aprendendo com a própria história. São Paulo: Paz e Terra, 2011b.

FREIRE, Paulo; GUIMARÃES, Sérgio. Dialogando com a própria história. São Paulo: Paz e Terra, 2011c.

GOMES, Nilma Lino. Educação, relações étnico-raciais e a Lei 10.639/03. Portal Geledés. [S. I. s. n.], 27 ago. 2011. Disponível em: https://www.geledes.org.br/educacao-relacoes-etnicoraciais-e-a-lei-1063903/. Acesso em: 6 abr. 2020.

GONZALEZ, Soler. Educação ambiental autopoiética entre manguezais, redes cotidianas escolares e práticas pesqueiras. In: REUNIÃO NACIONAL DA ASSOCIAÇÃO NACIONAL DE PÓSGRADUAÇÃO E PESQUISA EM EDUCAÇÃO, 36., 2013, Goiânia. Anais [...]. Goiânia:

Universidade Federal de Goiás, Campus Samambaia/UFG, 2013a.

GONZALEZ, Soler. Educação ambiental autopoiética com as práticas do bairro Ilha das Caieiras entre os manguezais e as escolas. 2013. 159 f. Tese (Doutorado em Educação) Centro de Educação, Universidade Federal do Espírito Santo, Vitória, 2013b.

GONZALEZ, Soler; TRISTÃO, Martha. Educação ambiental autopoiética com oficinas de mapas entre os manguezais e os cotidianos escolares da llha das Caieiras. In: ENCONTRO DE PESQUISA EM EDUCAÇÃO DA REGIÃO SUDESTE, 11., 2014, São João Del Rei. Anais [...]. São João Del Rei, MG: Universidade Federal de São João Del Rei, 2014.

GONZALEZ, Soler; RAMOS, Andreia Teixeira. Cartografia Social da Educação Ambiental no/do Município e Cariacica: Possibilidades emergentes para a Formação de Comunidades Sustentáveis. In: ENCONTRO DE PESQUISA EM EDUCAÇÃO DA REGIÃO SUDESTE, 10., 2011, Rio de Janeiro. Anais [...]. Rio de Janeiro: Unirio, Pós-Graduação em Educação na Região Sudeste em suas Múltiplas Dimensões, Rio de Janeiro, 2011.

GONZALEZ, Soler; RAMOS, Andreia Teixeira. Humberto Maturana e seus atravessamentos com a educação ambiental e formação de educadores/as. In: SEMINÁRIO INTERNACIONAL REDES, 7., 2013, Rio de Janeiro. Anais [...]. Rio de Janeiro/RJ: UERJ, $2013 a$.

GONZALEZ, Soler; RAMOS, Andreia Teixeira. Cartografias das práticas cotidianas em educação ambiental em Aracruz/ES: problematizando saberesfazeres socioambientais na atualidade. In: Encontro de pesquisa em educação ambiental (EPEA), 7., 2013, Rio Claro-SP. Anais [...]. Rio Claro-SP: Unesp, 2013b. 
GONZALEZ, Soler; RAMOS, Andreia Teixeira. Educação Ambiental autopoiética em redes de conversações na vida cotidiana. Textura, n. 30, jan./abr. 2014.

GONZALEZ, Soler; RAMOS, Andreia Teixeira. Educação ambiental, manguezais, cotidianos escolares, práticas pesqueiras e outros espaços de convivência e de formação de professores/as. In: Reunião Nacional da Associação Nacional de Pós-graduação e Pesquisa em Educação, 37., 2015, Florianópolis-SC. Anais [...]. Florianópolis-SC: UFSC, 2015a.

GONZALEZ, Soler; RAMOS, Andreia Teixeira. Narradores da maré: Educação ambiental e as artes de narrar, morar, pescar e cozinhar com os manguezais e cotidianos escolares. In: Seminário Internacional, 8., 2015, Rio de Janeiro. Anais [...]. Rio de Janeiro-RJ: UERJ, 2015b.

GONZALEZ, Soler; RAMOS, Andreia Teixeira. Potencial político e pedagógico de um projeto de pesquisa, ensino e extensão com os cotidianos escolares, práticas do bairro e manguezais. In: Congresso Internacional de Educação, 1., 2016, Sorocaba-SP. Anais [...]. Sorocaba: UNISO, 2016.

GONZALEZ, Soler; RAMOS, Andreia Teixeira. Narradores da maré: práticas pedagógicas por entre manguezais, comunidades e cotidianos escolares. In: Seminário Internacional as Redes Educativas e as Tecnologias, 10., 2019, Rio de Janeiro. Anais [...]. Rio de Janeiro-RJ: UERJ. 2019a.

GONZALEZ, Soler; RAMOS, Andreia Teixeira. Há uma horta no meio da cidade. QUAESTIO: Revista de Estudos em Educação, [S. I.], v. 21, n. 1, p. 157-178, 2019b. Disponível em: http://periodicos.uniso.br/ojs/index.php/quaestio/article/view/3514. Acesso em: 17 nov. 2021.

GONZALEZ, Soler; RAMOS, Andreia Teixeira; RANGEL, Iguatemi Santos. Educação Ambiental e Formação de Professores numa perspectiva Autopoiética. In: Endipe: encontro nacional de didática e prática de ensino, 16., 2012, Campinas, São Paulo. Anais [...]. Campinas-São Paulo: UNICAMP, 2012a.

GONZALEZ, Soler; RAMOS, Andreia Teixeira; RANGEL, Iguatemi Santos. Educação Ambiental numa perspectiva autopoiética e as Redes de Conversações na Formação de Educadores/as. In: Reunião Anual da Associação Nacional de Pós-Graduação e Pesquisa em Educação, 35. , Grupo de Trabalho 22 - Educação Ambiental, 2012, Galinhas, Pernambuco. Anais [...]. Porto De Galinhas-Pernambuco: ANPEd, 2012b.

GONZALEZ, Soler; RAMOS, Andreia Teixeira. Narradores da maré: práticas pedagógicas de um projeto de extensão, ensino e pesquisa, por entre manguezais, comunidades ribeirinhas e cotidianos escolares. In: CID, Eduardo Fausto Kuster; GOMES, Eduardo Rodrigues; OLIVEIRA, Hudson Cássio Gomes de; FIGUEIRAS, Marcio de Paulo (org.). Abordagens 
territoriais e práticas pedagógicas em territórios pesqueiros. 1 ed. Vitória: Cousa, 2018, v. 1, p. 1-185.

GONZALEZ, Soler; SILVA, Pauliano Roberto Martins da. Narradores da Maré: estudo e produção de mapas digitais com os saberes socioambientais e geográficos de comunidades tradicionais dos catadores de caranguejos e das paneleiras do Bairro Goiabeiras Velha. In: JORNADA DE INICIAÇÃO CIENTÍFICA DA UFES, 2016, Vitória-ES. Anais [...]. Vitória: [s. n.], 2016. ISSN: 2357-7746.

GONZALEZ, Soler; SILVA, Pauliano Roberto Martins. Momentos e acontecimentos da história ambiental e das tragédias ecológicas na Bacia do Rio Doce narrados por meio de fotografias, notícias e vídeos. In: JORNADA DE INICIAÇÃO CIENTÍFICA DA UFES, 2020, Vitória-ES. Anais [...]. Vitória: [s. n.], 2020. ISSN: 2357-7746.

GONZALEZ, Soler; NOGUEIRA, Gabriel Silva. Narradores da Maré: perpetuação dos saberes populares e tradicionais dos catadores de caranguejo da Baía de Vitória e a produção de vídeo documentário experimental. In: JORNADA DE INICIAÇÃO CIENTÍFICA DA UFES, 2017, Vitória-ES. Anais [...]. Vitória: [s. n.], 2017. ISSN: 2357-7746.

GONZALEZ, Soler; LEITE, Lucas de Souza. Perspectivas ecologistas nas narrativas e histórias de vida contadas pelas paneleiras de Goiabeiras e suas contribuições com a formação de educadores/a. In: JORNADA DE INICIAÇÃO CIENTÍFICA DA UFES, 2017, Vitória-ES. Anais [...]. Vitória: [s. n.], 2017. ISSN: 2357-7746.

GONZALEZ, Soler; LEITE, Lucas de Souza. Educação ambiental, meio ambiente, representações sociais, narrativas e práticas pedagógicas nos cotidianos escolares. In: JORNADA DE INICIAÇÃO CIENTÍFICA DA UFES, 2018, Vitória-ES. Anais [...]. Vitória: [s. n.], 2018.

GURI. Direção: Adriano Monteiro. Roteiro: Adriano Monteiro. Produção: Adriano Monteiro. [S. I. s. n.], 2019. 1 vídeo (13 min). Disponível: https://www.facebook.com/CurtaGuri/. Acesso em: 12 ago. 2021.

GRUPO DE PESQUISA TERRITÓRIOS DE APRENDIZAGENS AUTOPOIÉTICAS. Espelho. Diretório dos grupos de pesquisa no Brasil - Lattes. In: CNPq. [S. I. s. n.], 2014. Disponível em: dgp.cnpq.br/dgp/espelhogrupo/3496160664481516. Acesso em: 12 ago. 2021.

GPS ESSENTIALS. In: GPSESSENTIALS. Disponível em: https://www.gpsessentials.com/. Acesso em: 12 ago. 2021.

GUIMARÃES, Leandro Belinaso; KRELLING, Aline Krelling; BRACELOD, Valdo (org.). Tecendo a educação ambiental na arena cultural. Petrópolis, RJ: DP et Alii, 2010. 
GUIMARÃES, Leandro Belinaso et al. (org.). Ecologias inventivas: conversas sobre educação. Santa Cruz do Sul: EDUNISC, 2012.

HOOKS, bell. Ensinando a transgredir: a educação como prática de liberdade. São Paulo: Editora WMF Martins Fontes, 2013.

INSTITUTO DO PATRIMÔNIO HISTÓRICO E ARTÍSTICO NACIONAL (BRASIL). Ofício das Paneleiras de Goiabeiras [Instituto do Patrimônio Histórico e Artístico Nacional]. Brasília, DF: IPHAN, 2006. Disponível em: http://portal.iphan.gov.br/pagina/detalhes/51. Acesso em: 12 ago. 2021.

JESUS, Carolina Maria de. Quarto de despejo: diário de uma favelada. São Paulo: Ática, 2014.

JESUS, Victor de. Racializando o olhar (sociológico) sobre a saúde ambiental em saneamento da população negra: um continuum colonial chamado racismo ambiental. Saúde e Sociedade, São Paulo, v. 29, n. 2, e180519, 2020.

KBELA. Direção: Yasmin Thayná. Roteiro: Yasmin Thayná. Assistente de produção: Douglas Bolzan. [S. I. s. n.], 2015. (21 min 45 s). Disponível em:

https://www.youtube.com/watch?v=LGNIn5v-3cE. Acesso em: 12 ago. 2021.

KRENAK, Ailton. Ideias para adiar o fim do mundo. São Paulo: Companhias das Letras, 2019. MATURANA, Humberto. A ontologia da realidade. Belo Horizonte: Editora UFMG, 1999.

MATURANA, Humberto. Cognição, ciência e vida cotidiana. Belo Horizonte: Editora UFMG, 2006.

MAULIN, Gilfredo Carrasco. Lugares e tempos em narrativas de uma educação ambiental pós-colonial no Sítio dos Crioulos-Jerônimo Monteiro-ES. 2013. 216 f. Tese (Doutorado em Educação) - Universidade Federal do Espírito Santo. Centro de Educação.

MULHERES de Barro. Direção: Edileuza Penha de Souza. Produção: Jamilda Bento. Roteiro: Edileuza Penha de Souza. [Espírito Santo]: Hysteria, 2014. 1 vídeo (26 min). Disponível em: https://www.youtube.com/watch?v=4faXQjAZXVY\&t=38s. Acesso em: 27 abr. 2019.

NARRADORES de Javé. Direção de Eliane Caffé. Rio de Janeiro: Bananeira Filmes / Gullane Filmes / Laterit Productions / RioFilme, 2003. 1 vídeo (100 min). Disponível em: https://www.youtube.com/watch?v=Trm-CyihYs8\&t=4s. Acesso em: 3 maio 2019.

NARRADORES DA MARÉ. In: FACEBOOK. Espírito Santo, [página criada em 2014] 27 out. 2014. Disponível em: https://www.facebook.com/Narradores-da-Mar\%C3\%A9880737971944702. Acesso em: 12. ago. 2021. 
NARRADORES DA MARÉ. In: BLOGSPOT. Espírito Santo, [página criada em 2014] 27 out. 2014. Disponível em: http://narradoresdamare.blogspot.com/. Acesso em: 12 ago. 2021.

NARRADORES DA MARÉ. In: INSTAGRAM. [S. I.], [página criada em 2020] Disponível em: https://www.instagram.com/narradoresdamare/?hl=pt-br. Acesso em: 12 ago. 2021.

NARRADORES DA MARÉ. In: YOUTUBE. [S. I.], [página criada em 2017] 3 fev. 2015. Disponível em: https://www.youtube.com/channel/UCat6MvayMz7-YRntXS2TxDw. Acesso em: 12 ago. 2021.

NARRADORES DA MARÉ. In: SPOTIFY. [S. I.], [página criada em 2021] Disponível em: https://open.spotify.com/show/512E8eKQkvNbJXxBfLGOEt. Acesso em: 12 ago. 2021.

OLIVEIRA, Inês Barbosa de. et al. (org.). Narrativas: outros conhecimentos, outras formas de expressão. Petrópolis, RJ: DP et Alii e Faperj, 2010.

RAMOS, Andreia Teixeira; GONZALEZ, Soler. Educação ambiental numa perspectiva autopoiética na formação de educadores/as. Pró-discente (Online), v. 18, p. 52-65, 2012. Disponível em: https://periodicos.ufes.br/prodiscente/issue/view/381. Acesso em: 12 ago. 2021.

RAMOS, Andreia Teixeira. Educação ambiental entre práticas culturais cotidianas dos mascarados do congo. In: REUNIÃO NACIONAL DA ASSOCIAÇÃO NACIONAL DE PÓSGRADUAÇÃO E PESQUISA EM EDUCAÇÃO, 36., 2013, Goiânia. Anais [...]. Goiânia: Universidade Federal de Goiás, Campus Samambaia/UFG, 2013a.

RAMOS, Teixeira Andreia. Educação ambiental entre os carnavais dos amores com os mascarados do congo de Roda D’Água. 2013. 142 f. Dissertação (Mestrado em Educação) Centro de Educação, Universidade Federal do Espírito Santo, Vitória/ES, 2013b.

RAMOS, Andreia Teixeira; TRISTÃO, Marta. Educação Ambiental entre brincadeiras com os mascarados do congo nas oficinas culturais com os cotidianos escolares. In: ENCONTRO DE PESQUISA EM EDUCAÇÃO DA REGIÃO SUDESTE, 11., 2014, São João Del Rei. Anais [...]. São João Del Rei, MG: Universidade Federal de São João Del Rei, 2014.

RAMOS, Andreia Teixeira. Mulheres no congo do Espírito Santo: práticas de re-existência ecologista com os cotidianos escolares. 2018. 319 f. Tese (Doutorado em Educação) Programa de Pós-Graduação em Educação da Uniso, Universidade de Sorocaba, Sorocaba, São Paulo, 2018.

RAMOS, Andreia Teixeira. Mulheres do congo: educação e outras ecologias. In: REUNIÃO DA ASSOCIAÇÃO NACIONAL DE PÓS-GRADUAÇÃO E PESQUISA EM EDUCAÇÃO- SUDESTE, 14., 
2020, Rio de Janeiro. Anais [...]. Rio de Janeiro: Programas de Pós-Graduação PropED, PPGedu e PPGECC, 2020.

RAMOS, Andreia Teixeira. Geografia dos afetos - cartas, cartões postais, diário de campo e caderno de uma pesquisadora. Vitória: Pedregulho, 2021. 196 p. Disponível em:

https://www.editorapedregulho.com.br/downloads. Acesso em: 6 jul. 2021.

RAMOS, Andreia Teixeira; GONZALEZ, Soler. Práticas pedagógicas dialógicas como possibilidade de criação de currículos nos cotidianos escolares. Revista Espaço do Currículo, v. 13, p. 583-591, 2020.

REIGOTA, Marcos. Ecologistas. Santa Cruz do Sul: Edunisc, 1999.

REIGOTA, Marcos. O que é Educação Ambiental. São Paulo: Brasiliense, 2012. (Coleção Primeiros Passos; 292).

REIGOTA, Marcos. Aspectos teóricos e políticos das narrativas: ensaio pautado em um projeto transnacional. In: CORDEIRO, Rosineide; KIND, Luciana (org.). Narrativas, gênero e política. Curitiba: CRV, 2016. p. 49-66.

REIGOTA, Marcos; PRADO, Bárbara Heliodora Soares do. Educação ambiental: Utopia e práxis. São Paulo: Cortez, 2008.

RIBEIRO, Marcia Cristina Mazocco. Entre fios, nós e educações ambientais: narrativas ecologistas de mulheres de Cariacica. Dissertação (Mestrado Profissional em Educação) Centro de Educação, Universidade Federal do Espírito Santo, Vitória, 2021.

RIBEIRO, Marcia Cristina Mazocco. Trajetórias de mulheres nos processos de implementação de uma política municipal de educação ambiental. In: REUNIÃO DA ASSOCIAÇÃO NACIONAL DE PÓS-GRADUAÇÃO E PESQUISA EM EDUCAÇÃO- SUDESTE, 14., 2020, Rio de Janeiro. Anais [...]. Rio de Janeiro: Programas de Pós-Graduação PropED, PPGedu e PPGECC, 2020.

SANTOS, Edilene Machado dos. Cartografias e narrativas das educações ambientais e ecologias insubmissas nos cotidianos das mulheres na bacia do rio formate, Viana (ES). Dissertação (Mestrado Profissional em Educação) - Centro de Educação, Universidade Federal do Espírito Santo, Vitória, 2020, 212 p.

SANTOS, Edilene Machado dos; GONZALEZ, Soler. Práticas de educação ambiental: preservação de um rio nos cotidianos de uma comunidade. In: REUNIÃO DA ASSOCIAÇÃO NACIONAL DE PÓS-GRADUAÇÃO E PESQUISA EM EDUCAÇÃO- SUDESTE, 14., 2020, Rio de Janeiro. Anais [...]. Rio de Janeiro: Programas de Pós-Graduação PropED, PPGedu e PPGECC, 2020. 
SILVEIRA, Roberto Márcio da. Geografia das cores: práticas pedagógicas libertárias e ecologistas em educação nos cotidianos escolares. Dissertação (Mestrado Profissional em Educação) - Centro de Educação, Universidade Federal do Espírito Santo, Vitória, 2019, 160 p.

SILVEIRA, Roberto Márcio da Silveira; GONZALEZ Soler. Reinventando geografias e ecologias com a própria história: caderno-catálogo educativo. Vitória: Organização de Vitória, Universidade Federal do Espírito Santo, 2019. 34 p.

SOARES, Conceição; SANTOS, Edmeia. Artefatos tecnoculturais nos processos pedagógicos: usos e implicações para os currículos. In: ALVES, Nilda. Libâneo, José Carlos. Temas de Pedagogia: diálogos entre didática e currículo. São Paulo: Editora Cortez, 2012. p. 308-330.

UM OLHARPASSARINHO sobre a comunidade, os manguezais e suas ecologias. Direção: Fledson Silva Farias. [Espírito Santo]: Flex Filmes Brasil, 2021b. 1 vídeo (22 min $36 \mathrm{~s}$ ). Disponível em: https://www.youtube.com/watch?v=dhUG1ncKHIY. Acesso em: 12 ago. 2021.

UNIVERSIDADE FEDERAL DO ESPÍRITO SANTO. Projeto de extensão no 161 - narradores da maré SIEX \#400927. Vitória: DEPS, 2014. Disponível em:

https://projetos.ufes.br/\#/projetos/161/informacoes. Acesso em: 12 ago. 2021. 